\title{
Characteristics of Wear and Rolling on Fiber Reinforced Metal at High Temperature
}

\author{
Tsuyoshi INOUE, ${ }^{1) *}$ Shigeru UCHIDA ${ }^{1)}$ and Shigeru OGAWA ${ }^{2)}$ \\ 1) Technical Research \& Development Bureau, Nippon Steel \& Sumitomo Metal Corporation, 20-1 Shintomi, Futtsu, Chiba, \\ 293-8511 Japan. \\ 2) Nippon Steel \& Sumitomo Metal Corporation, 20-1 Shintomi, Futtsu, Chiba, 293-8511 Japan.
}

(Received on March 3, 2015; accepted on May 18, 2015; originally published in Tetsu-to-Hagané, Vol. 100, 2014, No. 12, pp. 1523-1529)

\begin{abstract}
Possibility of applying new roll materials (FRM (Fiber Reinforced Metal) roll materials), which are consisted of high speed tool steel reinforced with alumina fiber, to work rolls for hot rolling process is investigated by several laboratory tests. The FRM roll material expected to have superior tribological and mechanical properties, have been manufactured using sintering method (Hot Isostatic Pressing process) with which ceramic content can be increased. Wear resistance and mechanical properties and hot rolling characteristics of the FRM roll materials were investigated. As the results, it was clarified that the FRM roll material had three times or more wear resistance, a little lower rolling force and friction coefficient, and good thermal crack resistance and higher tensile strength in comparison with conventional casting roll materials such as a high speed steel roll material. Therefore, FRM roll materials can expectantly be used for hot rolling mill as high performance roll materials instead of high speed steel roll material.
\end{abstract}

KEY WORDS: hot rolling; work roll; fiber reinforced metal; high speed steel roll; wear

\section{Introduction}

According to increase in production of a high strength steel and productivity for hot rolling in steel manufacturing process, improvement of characteristics on wear, seizure and deterioration resistance of a work roll material is expected. A high speed steel (HSS) roll material which has $\mathrm{MC}$ type carbide and eutectic carbide $\left(\mathrm{M}_{7} \mathrm{C}_{3}\right.$ as for example) is mainly used for hot rolling roll. The HSS roll material includes many hard carbides in comparison with a high chromium cast roll material used before. Therefore, it has been clarified that HSS roll material has good performance on wear and seizure resistance. In the early 1990s, since the HSS roll started to be used for hot rolling roll, several operational problems were occurred on usage of the HSS roll. But the HSS roll has been used in hot rolling mill except for backward stand by improvements of compositions of the HSS roll and optimization of conditions of manufacturing process of the HSS roll. ${ }^{1-5)}$

In order to improve tribological characteristics of work roll used in hot rolling mill, it seems that increasing of a hard phase such as a carbide in a roll material is effective. However, it is difficult to make the amount of carbide phase (for example, $\mathrm{MC}$ carbide or $\mathrm{M}_{7} \mathrm{C}_{3}$ carbide) increase drastically by means of changing of compositions of a roll material using a continuous pouring casting process (CPC process) and centrifugal casting process known as repre-

\footnotetext{
* Corresponding author: E-mail: inoue.87a.tsuyoshi@jp.nssmc.com DOI: http://dx.doi.org/10.2355/isijinternational.ISIJINT-2015-123
}

sentative manufacturing method for the HSS roll. Recently, development of a new hot rolling roll that contains the hard phase much more than usual HSS roll has been reported. As these new rolls are manufactured by sintering process not casting one, the content of ceramics (hard phase) is increased in comparison with the HSS roll made by casting process. As the new roll material, a cermet roll that is consisted of WC and Co mainly, ${ }^{6,7)}$ used for wire rod rolling roll, and a fiber reinforced metal roll (FRM roll) ${ }^{8,9)}$ that is mixed a ceramic fiber in the HSS roll material have been reported. The FRM roll is proposed with intent to keep mechanical properties such as fracture toughness and heat cracking resistance to the casting roll materials level as well as to improve tribological properties such as wear resistance, by means of mixing ceramic fiber not but ceramic powders with metal powders. It has been obvious that FRM roll which is mixed alumina fiber with HSS steel powder has two times or more of wear resistance than usual HSS roll material made by casting process as well as mechanical properties keep to similar level of casting roll.

In this report, in order to clarify possibility that FRM roll material can be used for work roll of hot rolling finishing train, influence of a content and aspect ratio of ceramic fiber in FRM roll material on wear-resistance and rolling properties in hot rolling conditions have been investigated by laboratory experimental approach. Especially differences of rolling load, friction coefficient and mechanical properties between the FRM roll material made by sintering process and the HSS roll one made by casting process were carefully investigated by experimental equipments in a laboratory. 
Because when the HSS roll was introduced to manufacturing hot rolling mill, peculiar rolling phenomenon that rolling load increased by MC carbides was occurred.

\section{Experimental Method}

\subsection{Trial of Making FRM Roll Materials}

In this study, ceramic fibers and HSS steel powders which were obtained from a commercial market easily were used for ingredients of FRM roll materials. It was chosen for the HSS steel powders to be SKH10 grade provided in JIS G 4403, made by atomizing method, and to be average diameter under 45 micrometers. At first, SiC fiber and alumina fiber were chosen for the ceramic fiber of FRM roll material. It was checked whether HSS steel powders mixed with these $\mathrm{SiC}$ fiber (diameter: 8 micrometers, long fiber was used) or alumina fiber (diameter: 10 micrometers, long fiber was used) could be sintered by hot press experimental equipment. In the sintering experiment, one axial hot press equipment was used. HSS steel powders mixed with $\mathrm{SiC}$ fiber or alumina fiber of 10 volume $\%$ was sintered by the hot press equipment, and FRM roll material samples of about $23 \mathrm{~mm}$ in width, $35 \mathrm{~mm}$ in length and $3 \mathrm{~mm}$ in thickness were made. The conditions of the hot press experiment were $1000^{\circ} \mathrm{C}$ in sintering temperature, $40 \mathrm{MPa}$ in pressure, 2 hours in keeping time of sintering temperature. Figure 1 shows SEM images of the cross section of microstructure of FRM roll material samples. The sample made from HSS powders and alumina fibers is keeping its shape of alumina fiber (as shown in Fig. 1(a) (A)), and alumina fibers are joined HSS matrix (as shown in Fig. 1(a) (C)) to alumina fibers without defects. (The defects mean that gap around boundary between HSS matrix of Fig. 1 (C) and SiC fibers of Fig. 1(b) (B).) But the sample made from HSS powders and $\mathrm{SiC}$ fibers is that the shape of SiC fibers is changing as shown in Fig. 1(b) (B) and reaction products are observed around the SiC fibers. Therefore it is considerable that the alumina fiber is suitable for making test piece of FRM roll materials on trial.

Two types of alumina fiber were used for ingredients of FRM roll materials. One was a purity of more than $95 \%$, alpha phase ratio of more than $50 \%$, a diameter of $8-10$ micrometers and average aspect ratio of about 50. Another was the same purity and alpha phase ratio as above-mentioned one, diameter of 3-7 micrometers and average aspect ratio of about 20-40 adjusted by ball mill. The ingredients of FRM roll materials were made from these two types of alumina fibers, mixing HSS powders with alumina fiber of
20 volume \% uniformly by a mixer. The ingredients of FRM roll materials were sintered by HIP (Hot Isostatic Pressing) equipment under conditions of temperature of 1000 degree $\mathrm{C}$, pressure of $98 \mathrm{MPa}$, and keeping time in sintering temperature of 3 hours. Then heat treatment under the same condition as HSS roll manufactured by casting process were done to the sintered FRM roll materials, shore hardness of them was adjusted about between 83 and 86. The hardness was almost similar to HSS roll material manufactured by casting process. Figure 2 shows microstructures of FRM roll materials. Black lines shown in Figs. 2(a) and 2(b) are alumina fibers, the other area is HSS matrix. FRM roll mate-

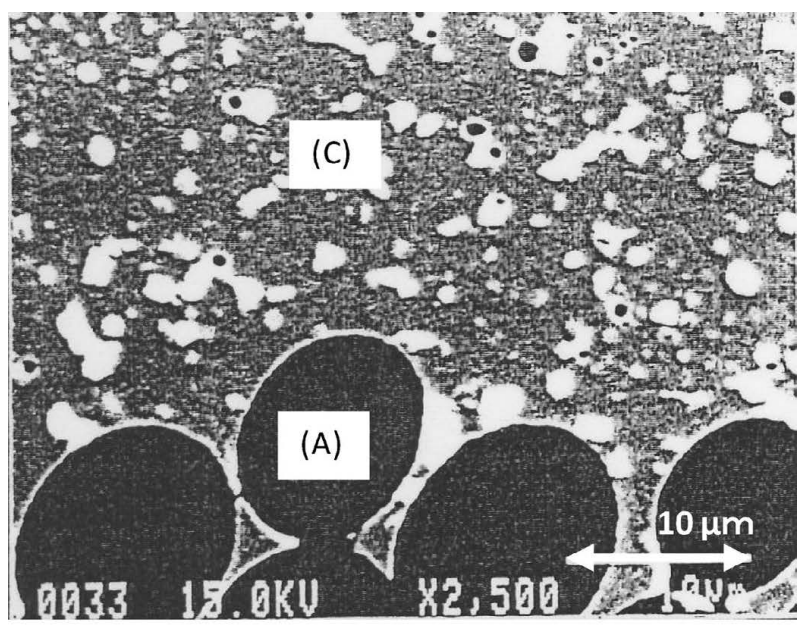

(a) $\mathrm{Al}_{2} \mathrm{O}_{3}$ fiber

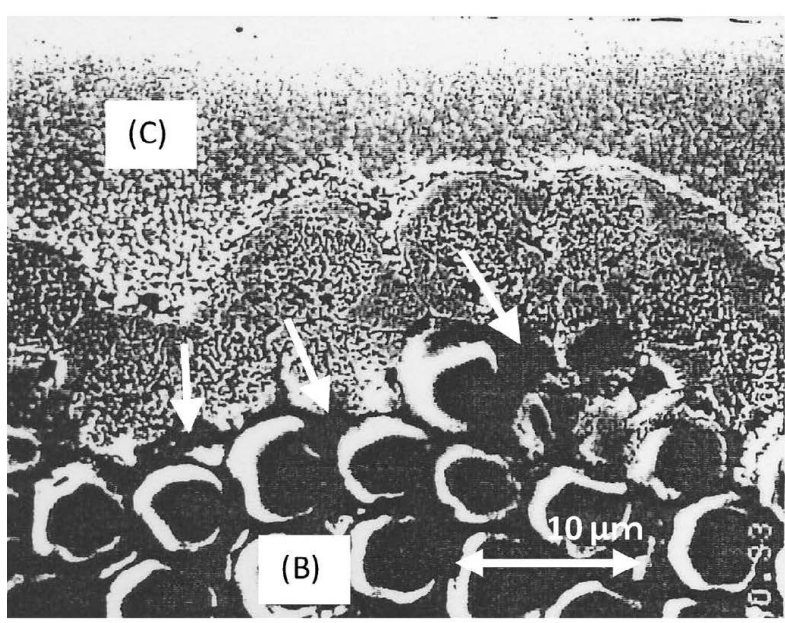

(b) $\mathrm{SiC}$ fiber

Fig. 1. Microstructure of FRM materials after hot press. (A) $\mathrm{Al}_{2} \mathrm{O}_{3}$ fiber, (B): $\mathrm{SiC}$ fiber, (C): High speed steel matrix.

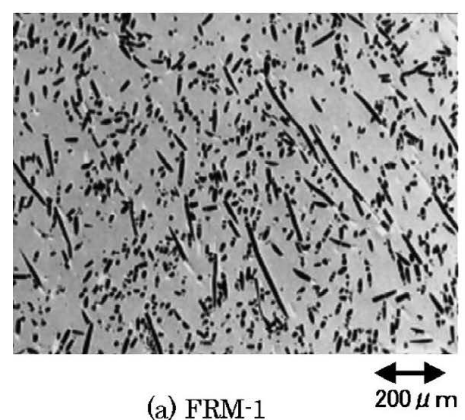

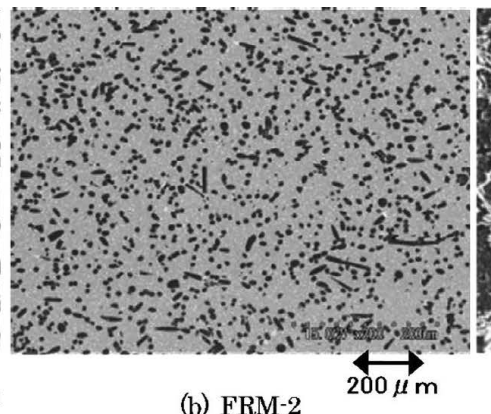

(b) FRM-2

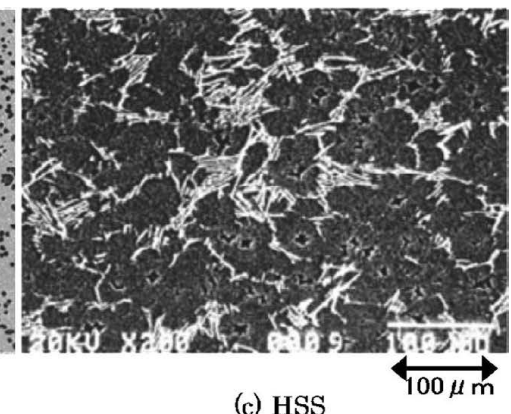

(c) HSS

Fig. 2. Microstructure of representative FRM materials made trially in this study. 
rials that alumina fibers were distributed in the HSS matrix uniformly without directivity were obtained. Table 1 shows compositions of test pieces of FRM roll materials made in this study on trial. FRM roll materials including alumina fiber of 10 volume $\%$ and 25 volume $\%$ were provided in order to investigate the influence of amount of alumina fiber on wear resistance of them. A test roll of FRM roll materials were made in sleeve type construction. The sleeve roll was consisted of a inner layer of Cr-Mo steel (JIS G 4053) and a outer layer of FRM roll material. The inner layer of $\mathrm{Cr}-\mathrm{Mo}$ steel is $60 \mathrm{~mm}$ in outer diameter, $45 \mathrm{~mm}$ in inner diameter, $100 \mathrm{~mm}$ in barrel length. The FRM roll material layer of the sleeve roll is $10 \mathrm{~mm}$ in thickness, joined to the barrel side of the inner layer by HIP treatment. Outer diameter of the test rolls of FRM roll material for hot rolling experiment is $80 \mathrm{~mm}$.

\subsection{Experimental Equipments and Its Conditions}

Wear resistance, hot rolling characteristics and heatcracking resistance of FRM roll materials were evaluated by means of hot rolling wear tester, hot coil rolling test mill and friction thermal shock test machine, in comparison with HSS roll materials made by casting process. A schematic diagram of the hot rolling wear tester is described in Fig. 3. A roll test disk of which different FRM roll material samples were inserted at 4 parts along the circumferential direction were provided, and rolling and sliding was loaded to 4 kinds of FRM roll materials simultaneously under the same frictional condition. Maximum wear depth of 4 test pieces of FRM roll materials was measured. Table 2-1 shows conditions of hot rolling wear test. Figure 4 shows schematic diagram of hot coil rolling test mill and Table 2-2 shows conditions of hot coil rolling test. Using the hot coil rolling test, wear resistance of FRM roll materials was evaluated comparing with roll wear depth obtained from difference of roll profile between before and after rolling. And characteristics of roll-

Table 1. Compositions of FRM samples.

\begin{tabular}{|c|c|}
\hline \multirow{2}{*}{ FRM-1 } & High speed steel roll material: 80 vol.\% \\
\hline & $\mathrm{Al}_{2} \mathrm{O}_{3}$ fiber (Aspect ratio: 50 ): 20 vol.\% \\
\hline \multirow{2}{*}{ FRM-2 } & High speed steel roll material: 80 vol.\% \\
\hline & $\mathrm{Al}_{2} \mathrm{O}_{3}$ fiber (Aspect ratio: $20-40$ ): 20 vol. $\%$ \\
\hline \multirow{2}{*}{ FRM-3 } & High speed steel roll material: 90 vol.\% \\
\hline & $\mathrm{Al}_{2} \mathrm{O}_{3}$ fiber (Aspect ratio: 50): 10 vol.\% \\
\hline \multirow{2}{*}{ FRM-4 } & High speed steel roll material: 75 vol.\% \\
\hline & $\mathrm{Al}_{2} \mathrm{O}_{3}$ fiber (Aspect ratio: 50 ): 25 vol. $\%$ \\
\hline
\end{tabular}

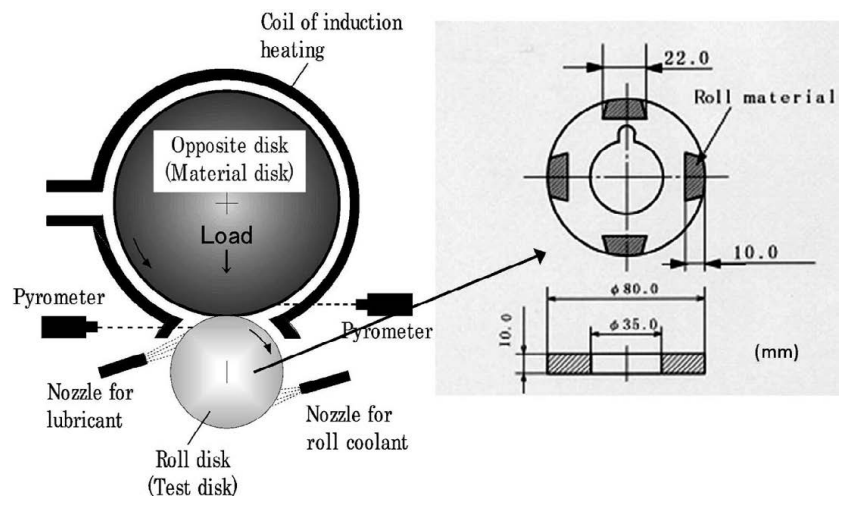

Fig. 3. Schematic diagram of hot rolling wear tester.

Table 2-1. Experimental conditions of hot rolling wear test.

\begin{tabular}{|c|c|c|}
\hline \multirow{3}{*}{$\begin{array}{l}\text { Roll disk } \\
\text { (Test piece) }\end{array}$} & Material & HSS, FRM \\
\hline & Temperature & $500^{\circ} \mathrm{C}$ \\
\hline & Size & $\varphi 80 \times 10 \mathrm{~mm}$ \\
\hline \multirow{3}{*}{$\begin{array}{c}\text { Material disk } \\
\text { (Opposite piece) }\end{array}$} & Material & S45C (JIS G 4051) \\
\hline & Temperature & $850^{\circ} \mathrm{C}$ \\
\hline & Size & $\begin{array}{l}\varphi 165 \times 15 \mathrm{~mm} \\
(\mathrm{R} 7.5 \mathrm{~mm})\end{array}$ \\
\hline \multicolumn{2}{|c|}{ Load } & $196 \mathrm{~N}$ \\
\hline \multicolumn{2}{|c|}{ Rotating velocity of roll disk } & $500 \mathrm{rpm}$ \\
\hline \multicolumn{2}{|c|}{ Slipping ratio } & $11 \%$ \\
\hline \multicolumn{2}{|c|}{ Lubrication } & Water (No Oil) \\
\hline \multicolumn{2}{|c|}{ Revolutions } & 5000 \\
\hline
\end{tabular}

Table 2-2. Experimental conditions of hot rolling test.

\begin{tabular}{ll}
\hline Roll Material & FRM, HSS roll \\
\hline RPCC (JIS G 3141) & Thickness: $1 \mathrm{~mm}$ \\
& Width: $50 \mathrm{~mm}$ \\
& Length: $1000 \mathrm{~m}$ \\
\hline Temperature of furnace & $1000^{\circ} \mathrm{C}\left(\mathrm{N}_{2}\right.$ atmosphere) \\
\hline Rolling velocity & $80 \mathrm{~m} / \mathrm{min}$. \\
\hline Tension & Entry side: $588 \mathrm{~N}$ \\
\hline Reduction & Delivery side: 1 177 N \\
\hline Roll coolant & $28-37 \%$ \\
\hline Lubrication & Water spray (at delivery side) \\
\hline
\end{tabular}

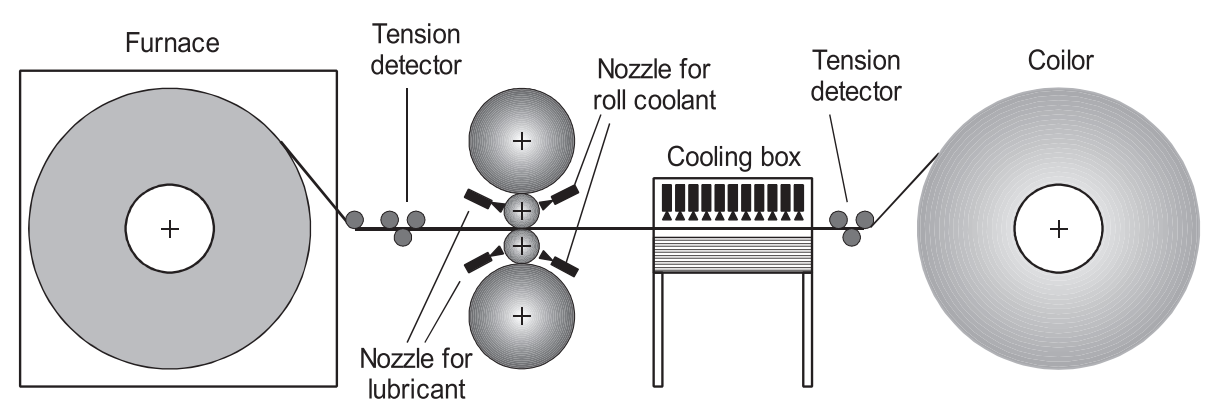

Fig. 4. Schematic diagram of hot coil rolling mill. 
ing load and forward slip was also investigated in the hot coil rolling test. The friction thermal shock test was carried out by the same way as Ohashi et al. ${ }^{11)}$ A frictional thermal shock was sharply added to surface of test pieces of FRM roll materials which is $20 \mathrm{~mm}$ in height, $20 \mathrm{~mm}$ in length and $30 \mathrm{~mm}$ in width, by means of passing steel rod $(5 \mathrm{~mm}$ in diameter and $40 \mathrm{~mm}$ in length) into gap of $3 \mathrm{~mm}$ between test piece of FRM roll material and opposite rotating disk. After that heat-cracking resistance of FRM and HSS roll materials was compared and evaluated by observing maximum depth of crack generated at the region added frictional thermal shock.

\section{Experimental Results and Considerations}

\subsection{Wear Resistance}

Figure 5 shows wear resistance of FRM roll materials made from different amount of alumina fiber (aspect ratio of about 50) in comparison with HSS roll material made by casting process and sintering process (HIP). In Fig. 5, wear resistance of each roll materials is shown with normalized value by wear resistance of HSS roll material made by casting process. Wear resistance of HSS roll material made by HIP is about two times than HSS roll material made by casting process, and wear resistance of FRM-1 sample is about four times than HSS roll material made by casting process. Wear resistance of FRM-2, which includes alumina fiber of 20 volume $\%$ and aspect ratio of $20-40$, has almost as same as wear resistance of FRM-1, which includes alumina fiber of 20 volume $\%$ and aspect ratio of 50. It is clear that wear resistance of FRM roll material is affected by content of alumina fiber obviously rather than by aspect ratio of alumina fiber. From the result that wear resistance of FRM-3, which includes alumina fiber of 10 volume $\%$ and 50 aspect ratio, is about middle value between FRM-1 and HSS(HIP), it is supported that wear resistance of FRM roll material is easily affected by content of alumina fiber rather than by aspect ratio of one. It is considerable that the content of alumina fiber which is harder than HSS matrix in FRM roll material is in proportion to ratio of alumina fiber area on the roll surface because alumina fibers are mixed in the HSS matrix uniformly. So it seems that increasing in ratio of alumina

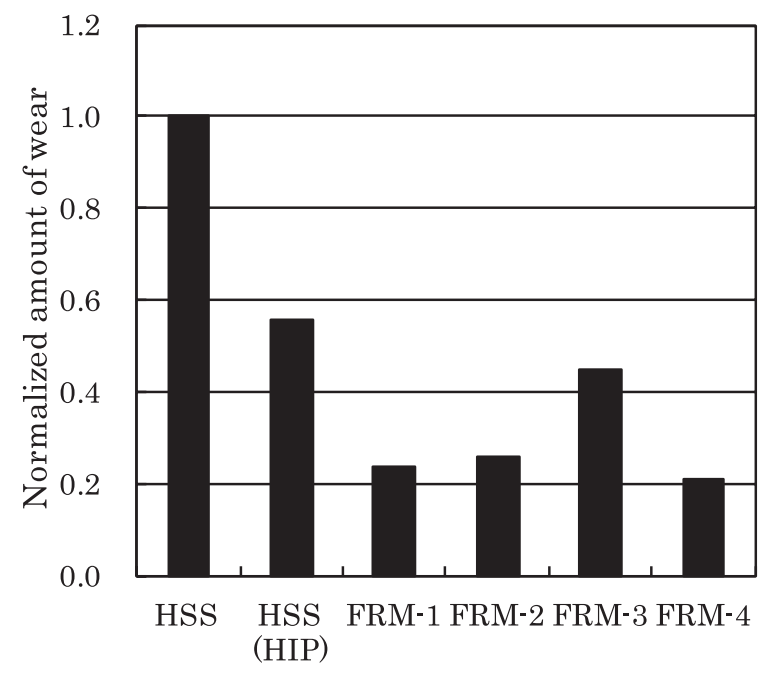

Fig. 5. Amount of wear by hot rolling wear test. fiber area on the roll surface is effective in improvement of wear resistance of roll material. However, wear resistance of FRM-4 which includes alumina fiber of 25 volume $\%$ is not so much improved in comparison with FRM-1 from the results of hot rolling wear test.

Figure 6 shows roll profiles measured after hot coil rolling test of four coils of $1000 \mathrm{~m}$ heated at 1000 degree C. Figure 7 shows wear depth measured from roll profiles indicated in Fig. 6. Against that wear depth of FRM-1 (aspect ratio: 50, alumina fiber: 20 volume $\%$ ) is $1.0-1.5$ micrometers, wear depth of FRM-2 is 1.5-2.0 micrometers, and wear depth of HSS(Cast) is 4.5-6.5 micrometers. Although there is a little difference of wear depth between FRM-1 and FRM-2 (these are different from aspect ratio of alumina fiber, but there are the same content of alumina fiber) in the hot coil rolling test, it is considerable that FRM roll material

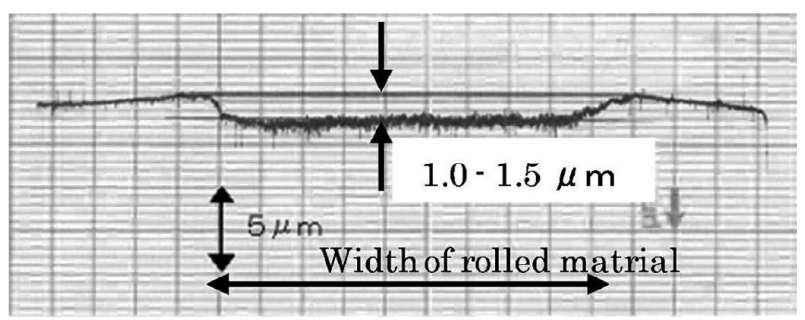

(a) FRM-1

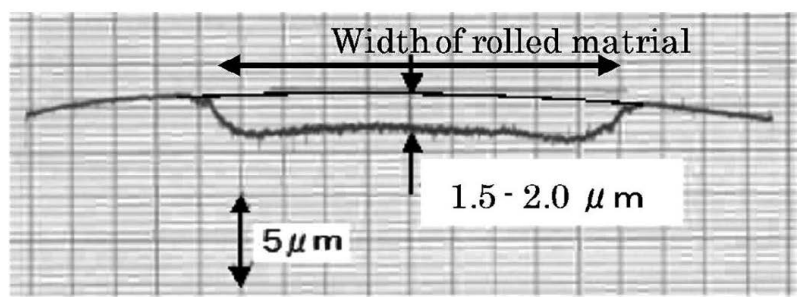

(b) FRM-2

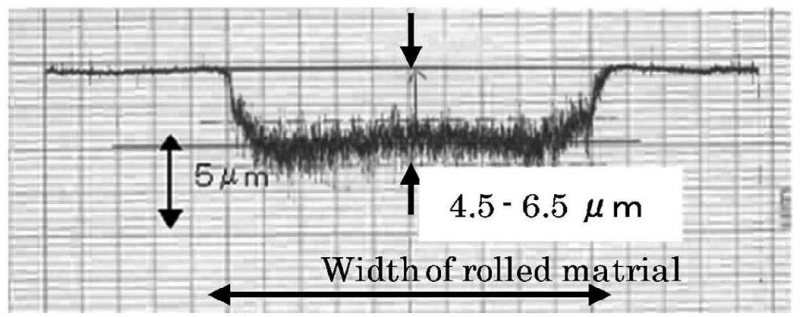

(c) HSS

Fig. 6. Roll profiles after hot coil rolling test.

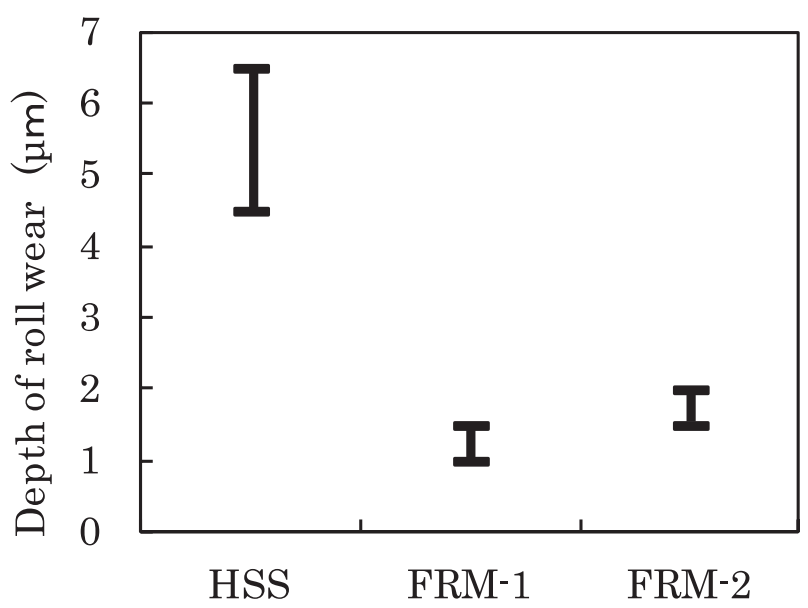

Fig. 7. Depth of roll wear by hot coil rolling test. 
has three times or more wear resistance in comparison with HSS(Cast) roll material. The reason why wear resistance of FRM roll materials is affected by aspect ratio of alumina fiber is now not clear, so because of clarification of this point it is necessary to investigate wear mechanism of FRM roll material by hot coil rolling test and so on.

\subsection{Characteristics of Hot Rolling}

Figure 8 shows rolling load per width plotted against reduction, and Fig. 9 shows forward slip and friction coefficient calculated by rolling model with measured forward slip and rolling load at the reduction of $36 \%$. The forward slip was obtained by roll mark method and friction coefficient was calculated using Orowan's rolling model to become equal forward slip and rolling load obtained by hot coil rolling test to ones obtained by calculation. Rolling load of FRM-2 is similar to or a little lower than one of HSS(Cast). Rolling load of FRM-1 and FRM-2 is almost the same level, therefore aspect ratio of alumina fiber does not affect to rolling load. Forward slip and friction coefficient of FRM-2 is lower than ones of HSS(Cast) in this hot coil rolling test, especially friction coefficient of FRM-2 is 0.04 lower than one of HSS(Cast). Generally friction coefficient in case of sliding of metal-to-metal is higher than one in case of sliding of ceramics-to-metal. So it is seemed that friction coefficient of FRM roll material becomes lower than one of HSS(Cast) roll material because that the area of

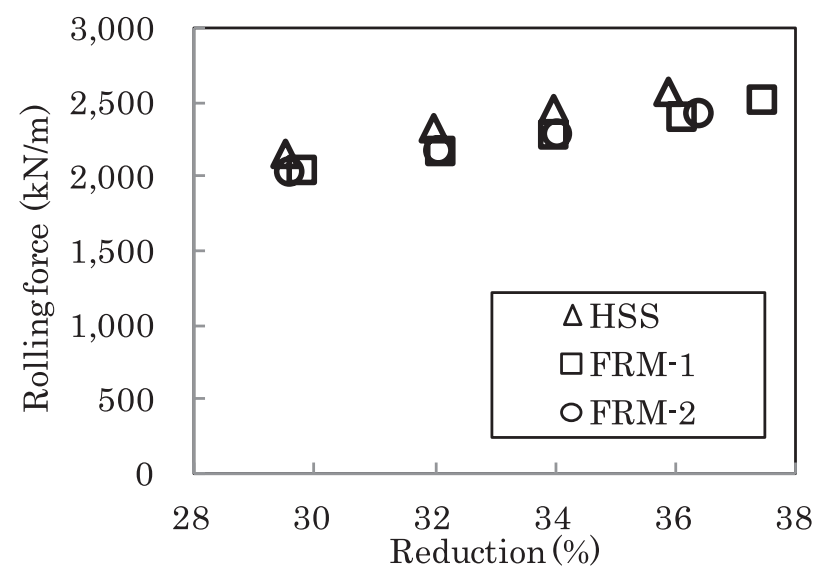

Fig. 8. Comparison of rolling load per unit width obtained by hot coil rolling test.

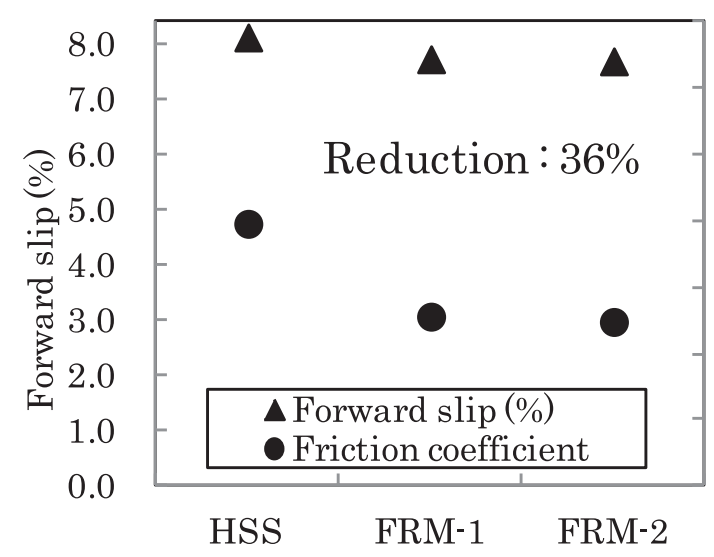

0.26

0.24

0.22

0.20

0.18

0.16

Fig. 9. Comparison of forward slip and friction coefficient obtained by hot coil rolling test. alumina fiber on frictional surface is larger than the area of carbide included in HSS(Cast) by adding alumina fiber of 20 volume $\%$ to HSS matrix.

Figure 10 shows surface roughness of roll after hot coil rolling test using heated steel at 1000 degree C. A initial surface roughness of roll was adjusted between $0.02 \mu \mathrm{m}$ $\mathrm{Ra}$ and $0.05 \mu \mathrm{m} \mathrm{Ra}$. A surface roughness of HSS(Cast) roll after rolling one coil of $1000 \mathrm{~m}$ increased to $0.48 \mu \mathrm{m} \mathrm{Ra}$. However the surface roughness of FRM-1 and FRM-2 roll after hot coil rolling test is $0.08 \mu \mathrm{m} \mathrm{Ra}$, smaller than one of HSS(Cast) roll in spite of difference of aspect ratio of alumina fiber. Although increasing in rolling distance, surface roughness of FRM roll almost keeps the same level as 0.08 $\mu \mathrm{m} \mathrm{Ra}$. When the HSS(Cast) roll material was introduced to hot strip mill in the past, MC carbides on the surface of HSS(Cast) roll became protrusions by reason of difference of wear rate between MC carbides and matrix. These protrusions caused increasing of friction coefficient. It was known that according to increasing of friction coefficient rolling load was increased and defects of product surface concerning with scale were cased. ${ }^{10)}$ However, because friction coefficient of FRM roll material tends to become smaller than friction coefficient of HSS(Cast) material, possibility that the problems about rolling force and defects of product surface become obviously very low when FRM roll material is used in manufacturing hot rolling mill.

Figure 11 shows SEM image of frictional region on FRM-2 roll surface observed after hot coil rolling test. On the surface of HSS(Cast) roll material, MC carbides distributing uniformly in the form of powder promotes abrasive wear of roll surface by which MC carbide removed from roll surface becomes abrasive particles. On the other hand, rolling pressure added to alumina fiber is smaller than one added to MC carbide under the condition of the same rolling load. Because area of alumina fiber in FRM roll material is larger than the area of MC carbides in HSS(Cast) roll material. So it is thought that frictional resistance is small in order that the abrasive cutting depth by MC carbides in HSS(Cast) roll material is deeper than the abrasive cutting depth of alumina fiber in FRM roll material when roll material contacts under the same rolling load. Also it is difficult to consider that alumina fiber encourage abrasive wear of

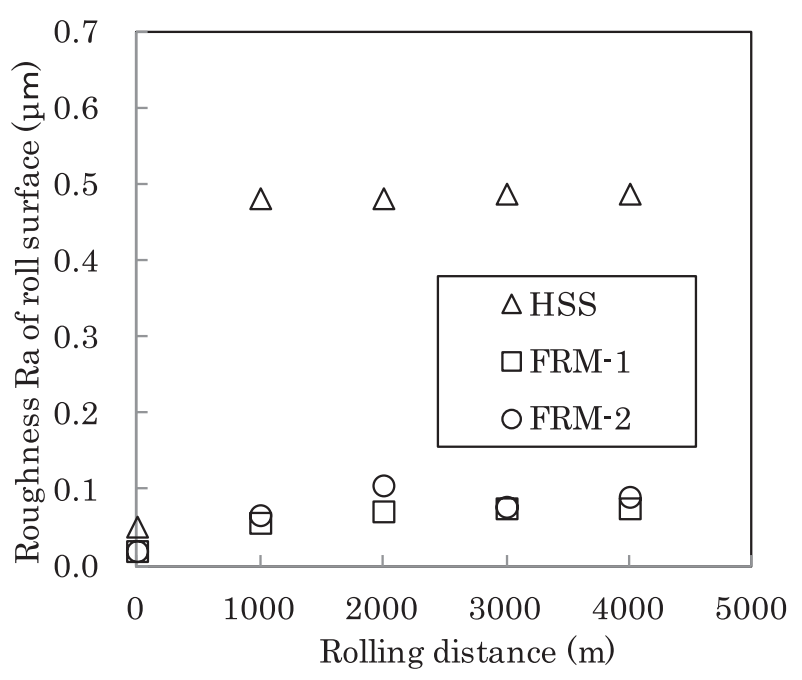

Fig. 10. Roughness Ra of roll surface after hot coil rolling test. 
roll surface by which alumina fiber is removed from FRM roll material surface, because depth that alumina fiber is cut into rolled material is shallow in comparison with $\mathrm{MC}$ carbides.

\subsection{Mechanical Properties}

Figure 12 shows representative microstructure images of cross section of thermal shock region at which some cracks were generated at FRM-1 and HSS(Cast) roll material surface layer after friction thermal shock test. In the HSS(Cast) roll material, several cracks of 100-150 micrometers in

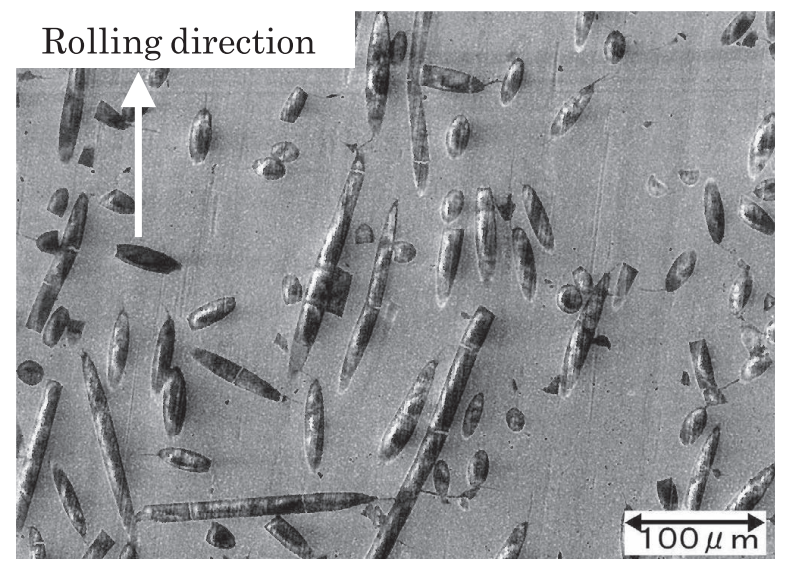

Fig. 11. SEM image of surface of FRM-1 roll sample after hot coil rolling test.

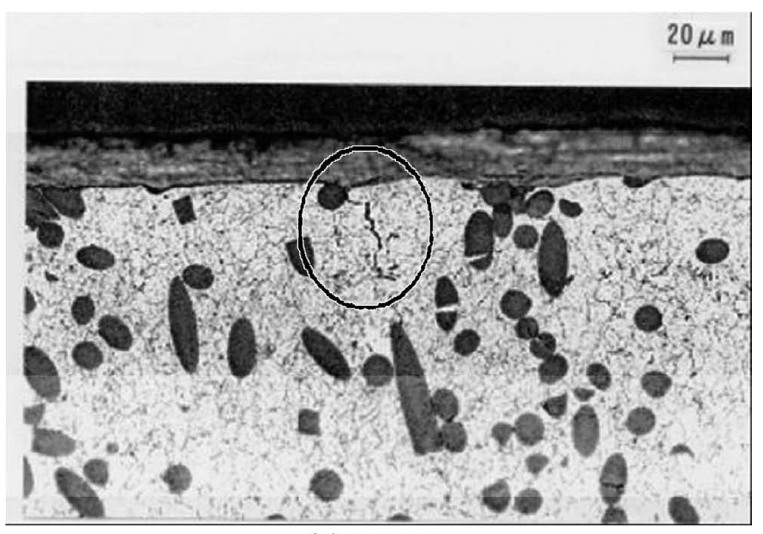

(a) FRM-1

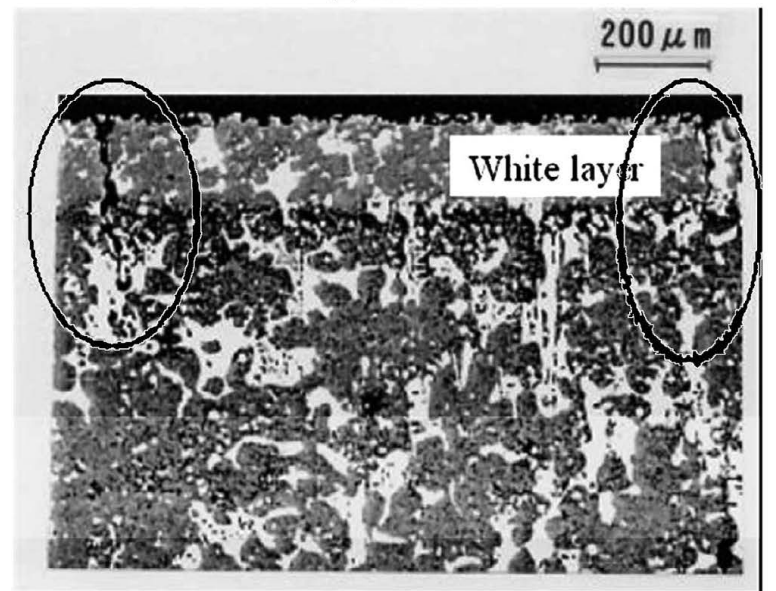

(b) HSS

Fig. 12. Microstructures of cross section of roll samples after thermal shock test. depth was propagating through a thermal affecting layer (white layer) from the surface. In the FRM-1 roll material, it was observed that the crack from the surface is propagating until the depth of 30-50 micrometers, moreover the propagation of the crack is stopping at the alumina fiber. Therefore thermal crack resistance of FRM roll material is improved by adding alumina fiber which stops crack propagation in comparison with HSS(Cast) roll material.

Figure 13 shows a tensile strength of FRM-2 including alumina fibers of 20 volume $\%$ and HSS(Cast) at room temperature with a value normalized against the tensile strength of HSS(Cast) roll material. It is clear that the tensile strength at room temperature of FRM-2 roll material is almost as same as one of HSS(Cast) roll material. FRM roll material which is different from aspect ratio of alumina fiber also has the similar tensile strength. Therefore it seems that tensile strength of FRM roll material is not so affected by difference of aspect ratio of alumina fiber. It is considerable that FRM roll materials made in this study have sufficient tensile strength when using for work roll of manufacturing hot rolling mill.

Figure 14 shows normalized joining strength between Cr-Mo steel (SCM) and FRM roll material and between HSS(Cast) roll material used for outer layer in work roll and SCM used for shaft core material. When FRM roll

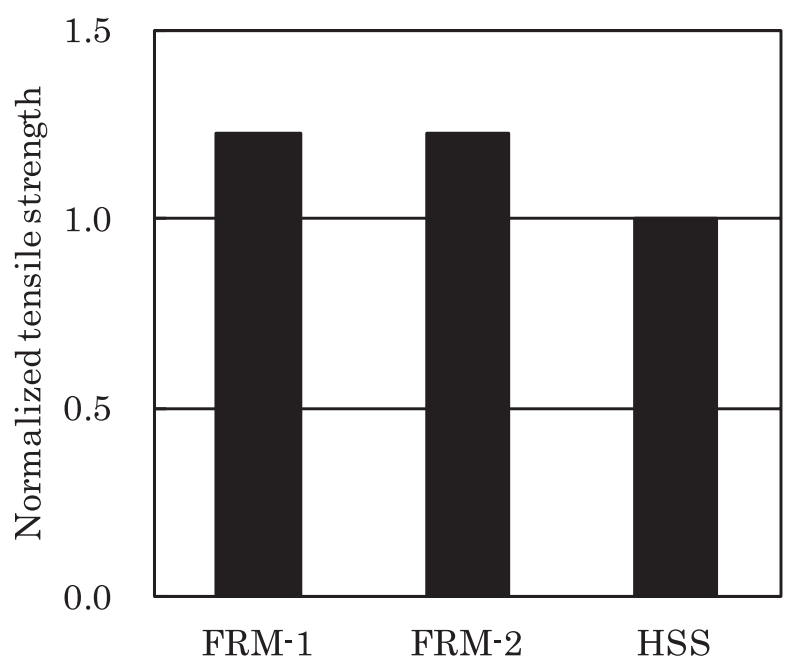

Fig. 13. Tensile strength of roll materials.

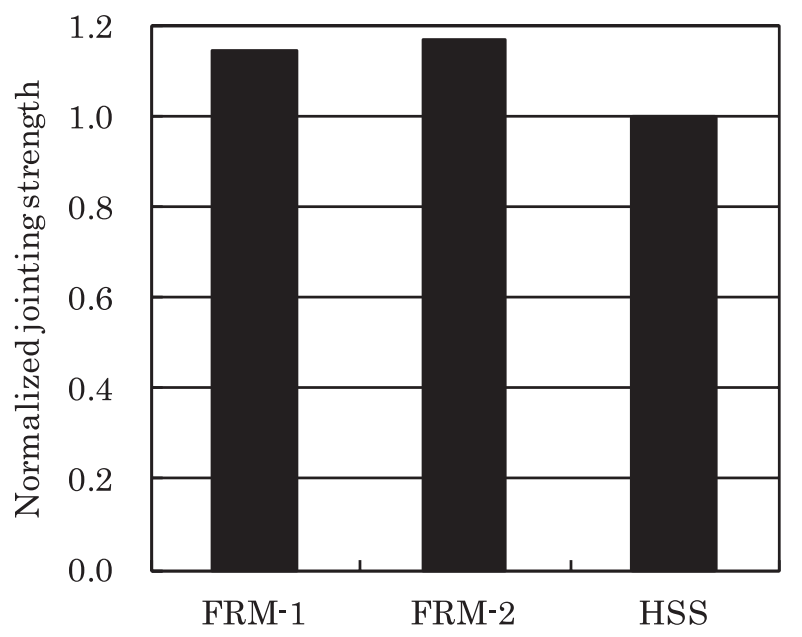

Fig. 14. Jointing strength between FRM and SCM. 
is actually manufactured as work roll for hot rolling mill, it is necessary to join FRM roll material to shaft core of $\mathrm{SCM}$ at sintering process by HIP equipment. In order to measure joining strength between FRM-2 and SCM, test pieces of tensile strength that boundary between FRM-2 and SCM locates the center of the test pieces were made. As the result of measurement of joining strength, as shown in Fig. 14, joining strength between FRM-2 and SCM is similar or more than the joining strength between HSS(Cast) and SCM. Also joining strength of FRM-1 which is different from aspect ratio of FRM-2 is almost the same level compared with FRM-2. So there is probably no problem to use FRM roll material in manufacturing hot rolling process.

\section{Conclusions}

As the new roll material used in hot rolling process instead of HSS roll material made by casting process, characteristics of wear resistance and hot rolling of FRM roll materials that is reinforced HSS roll material by alumina fiber was investigated by means of hot rolling wear tester and hot coil rolling test mill and so on. As the results of these experiments, several acknowledgements described below were obtained.

(1) It is clarified that wear resistance of FRM roll material which include alumina fiber of 20 volume $\%$ is three times or more than HSS roll material made by casting process by means of hot rolling wear test and hot coil rolling test. Content of alumina fiber into the FRM roll material affects its wear resistance rather than difference of aspect ratio of alumina fiber. Therefore it was obvious that wear resistance of FRM roll material did not so change by difference of aspect ratio of alumina fiber.

(2) In concerning with friction coefficient and rolling load, what FRM roll material is shortly smaller than HSS(Cast) roll material have been obvious. This phenomena is observed because of increasing area of alumina fiber on the roll surface, difference of aspect ratio of alumina fiber is not affected.

(3) FRM roll material has sufficient tensile strength and thermal crack resistance when using for work roll of manufacturing hot rolling mill, although FRM roll material contains many hard phases(alumina fiber) in comparison with HSS(Cast) roll material.

Therefore, there seems a sufficient possibility that FRM roll material is introduced as new work rolls in the hot rolling mills instead of HSS roll material. At this stage, FRM roll material can be only made in size of small test roll used in laboratory tester. It is thought that development of manufacturing technology for practical size of FRM roll is necessary to realize FRM roll used in manufacturing hot rolling mill.

\section{Acknowledgement}

We would like to express our appreciation, describing that part of this study was carried out with a subsidy of Ministry of Economy, Trade and Industry.

\section{REFERENCES}

1) Y. Sano, T. Hattori and M. Haga: ISIJ Int., 32 (1992), 1194.

2) M. Hashimoto, S. Otomo, K. Yoshida, K. Kimura, R. Kurahashi, T. Kawakami and T. Kouga: ISIJ Int., 32 (1992), 1202.

3) M. Hashimoto, T. Kawakami, T. Oda, R. Kurahashi and K. Hokimoto: Shinmittetsu Giho, 355 (1995), 76.

4) A. Noda, E. Matsunaga, T. Hattori and Y. Sano: Hitachi-KinzokuGiho, 13 (1997), 89.

5) Y. Sano: J. JSTP, 39 (1998), 2.

6) Y. Kamitani, T. Hattori, H. Tomita and Y. Sano: CAMP-ISIJ, 18 (2005), 1235.

7) Y. Kamitani, T. Hattori, Y. Sano, S. Fukushima, M. Eto and T. Sasaki: CAMP-ISIJ, 19 (2006), 993.

8) T. Inoue, S. Uchida, S. Ogawa, T. Kikuma, H. Tani and H. Sueyoshi: CAMP-ISIJ, 21 (2008), 1231.

9) T. Inoue, S. Uchida, S. Ogawa, T. Kikuma, H. Tani and H. Sueyoshi: CAMP-ISIJ, 22 (2009), 429.

10) K. Gotoh, H. Okada, T. Sasaki and T. Koide: Tetsu-to-Hagané, 84 (1998), 861.

11) S. Ohhashi, T. Ishiguro and H. Gotoh: Tetsu-to-Hagané, 77 (1991), 652 . 